\title{
Perforation behaviour of composites sandwich structures on low-velocity impact at oblique angles
}

\author{
S.H. Sheikh Md. Fadzullah ${ }^{1 *}$, O. Ifayefunmi ${ }^{2}$, Z. Mustafa ${ }^{3}$, G. Omar ${ }^{1}$ \\ and M.R. Mansor ${ }^{1}$
}

${ }^{1}$ Centre for Advanced Research on Energy (CARe), Faculty of Mechanical Engineering, Universiti Teknikal Malaysia Melaka, Hang Tuah Jaya, 76100 Durian Tunggal, Melaka, Malaysia.

*Email: hajar@utem.edu.my Phone: +6062346742; Fax: +6062346884

${ }^{2}$ Faculty of Engineering Technology, Universiti Teknikal Malaysia Melaka, Hang Tuah Jaya, 76100 Durian Tunggal, Melaka, Malaysia.

${ }^{3}$ Faculty of Manufacturing Engineering, Universiti Teknikal Malaysia Melaka, Hang Tuah Jaya, 76100 Durian Tunggal, Melaka, Malaysia.

\begin{abstract}
This paper presents the perforation behaviour of polyethylene terephthalate (PET) foam cored sandwich structures when subjected to quasi-static and dynamic loading at normal $\left(0^{\circ}\right)$ and oblique angles of $10^{\circ}$ and $20^{\circ}$. An instrumented drop-weight hammer rig was used with fully-clamped conditions for the low-velocity impact test with impact energy of $40 \mathrm{~J}$ and velocity of $3.78 \mathrm{~m} / \mathrm{s}$. Meanwhile, the quasi-static indentation test was carried out using a universal testing machine via an Instron 4505, at crosshead displacement rate of $1 \mathrm{~mm} / \mathrm{min}$, with boundary conditions similar to those of the dynamic test. Results obtained showed that the normal impact generated the highest peak force for both the first and second peaks, which are associated with the damage to the top and bottom skins of the sandwich structures. Moreover, regardless of whether the test was done on the normal or inclined angles, it was observed that the dynamic loading produced higher force magnitude in comparison to those of the quasi-static response, due to the enhanced strength and stiffness of the components because of the strain rate and inertia effects. However, in terms of the damage profiles, it is evident that the maximum damage area increased with the increase inclination angle as supported by simple geometric analysis. For the oblique impact cases, the damage was due to the combined effect of tensile, compression, and shear for impact at $10^{\circ}$. The damage occurred as a result of pure shearing for the $20^{\circ}$ impact case. In conclusion, the perforation behaviour at inclined angles allowed more area to be perforated in comparison to those of the normal cases.
\end{abstract}

Keywords: Low-velocity impact; oblique; perforation; composites; sandwich structures.

\section{INTRODUCTION}

Numerous research studies have focused on the impact response of composite laminates and sandwich structures since it is well established that impact events affect the mechanical performance of composite materials; e.g. by precipitating a reduction in the strength of the structure which can lead to catastrophic failure [1-7]. Under low-velocity 
impact, the damage is frequently barely visible (BVID) and often cannot be detected by Non-Destructive Testing (NDT). Impact events can occur during the manufacturing process and in-service operation as well as during the life of a structure or component. In addition, it should be noted that most impact events are non-normal or oblique in nature [8-12]. In addition, depending on the angle of incidence of the indenter with respect to the target, rebounding or ricocheting can occur [8-10]. To-date, a limited number of studies have focused on the oblique impact response of composites and sandwich structures [8, 9, 13-19]. Moreover, most of these works are dedicated to ballistic impact $[2,20]$. Wen et al. [21] highlighted three important steps of panel failure during deformation in a sandwich structure; these being (i) initial failure where one of the skins of the panel is fractured with or without considerable deformation of the core; (ii) penetration of the indenter through the thickness of the panel; and (iii) perforation of the panel when the whole of the indenter has emerged through the panel. In addition, there are three different failure modes associated with the initial failure; these being (i) indentation failure; (ii) core shear failure, and (iii) panel bending failure.

Zhou et al. [19] reported their findings to predict the perforation resistance of the sandwich panels when subjected to oblique impact. For a given type of sandwich panel, the normal impact exhibits the highest maximum impact force. The corresponding perforation energy was found to increase with impact angle. In addition, further investigation was made on the damage evolution, with the focus on the perforated panels made with cross-linked PVC sandwich composites and PET sandwich composites subjected to an oblique impact at incident angles of $0^{\circ}, 10^{\circ}, 20^{\circ}$, and $30^{\circ}$, respectively. The cross-sections revealed that impact occurring at the highest angle of inclination resulted in the greater surface area using a simple geometric analysis. Here, it was assumed that the indenter creates an elliptic entrance hole on the top surface of the target. The calculated surface area was found to increase by approximately $25 \%$ while the volume of the total area also increased by $16 \%$, in passing from normal impact $\left(0^{\circ}\right.$ to $30^{\circ}$ ). From these observations, it was argued that the change in perforation energy is associated with increasing impact angle. This paper seeks to examine the effect of increasing impact angle ranging from $0^{\circ}$ to $20^{\circ}$ on the perforation behaviour of PET foam cored sandwich structures when subjected to both quasi-static indentation test and dropweight impact at energies up to $40 \mathrm{~J}$.

\section{METHODS AND MATERIALS}

\section{Fabrication of the Sandwich Structures}

The top and bottom skins of the sandwich structures were manufactured in four plies of glass fibre reinforced epoxy with a stacking sequence of [0/90] with a nominal cured thickness of $1.0 \mathrm{~mm}$. The laminates were then placed on either side of the polyethylene terephthalate (PET) polymeric foam core, which is commercially available as AIREX® T92.100. The skin material is commercially available as SE84 unidirectional (E-glass) fibre reinforced epoxy resin prepreg with nominal ply thickness of $0.25 \mathrm{~mm}$. The PET foam core has a nominal apparent density of $115 \mathrm{~kg} / \mathrm{m}^{3}$ and thickness of approximately $20 \mathrm{~mm}$ each. The final cured dimensions of the sandwich structures were $150 \mathrm{~mm}(\mathrm{~L}) \times$ $150 \mathrm{~mm}(\mathrm{~W})$ with a cured thickness of $20 \mathrm{~mm}$. An illustration showing the hand lamination of the sandwich structures is given in Figure 1. The chemical properties of the skin and core materials are given in Tables 1 and 2, respectively. 


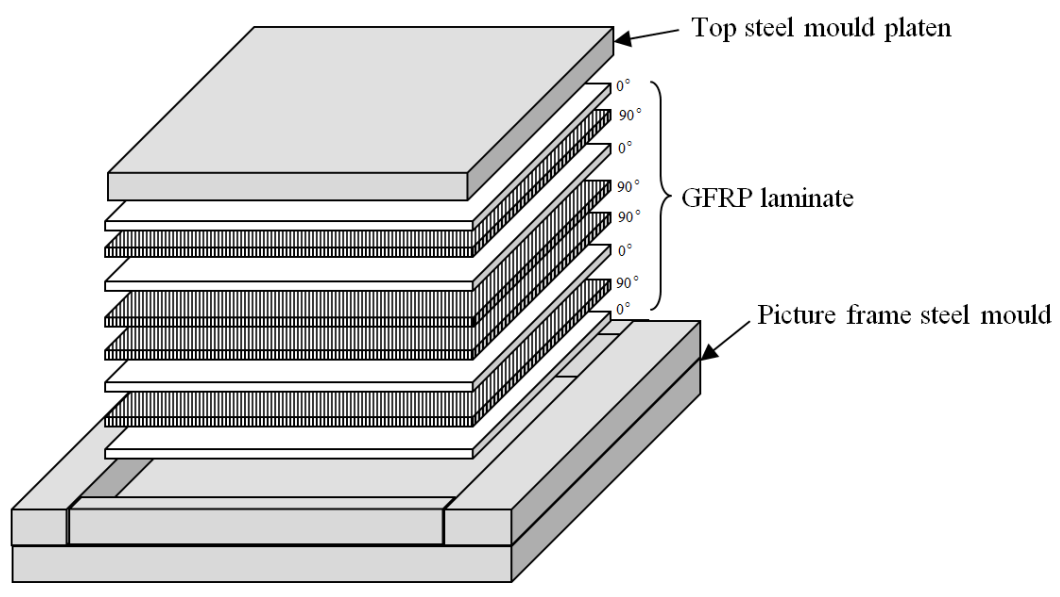

Figure 1. Illustration of the stacking sequence for an 8-ply composite laminate.

Table 1. Properties of the skin material (UD SE84 glass fibre-reinforced prepreg).

\begin{tabular}{ll}
\hline \multicolumn{1}{c}{ Properties } & \multicolumn{1}{c}{ Value } \\
\hline Tensile Strength & $1257 \mathrm{MPa}$ \\
Tensile Modulus & $47 \mathrm{GPa}$ \\
Interlaminar Shear Strength & $83 \mathrm{MPa}$ \\
Compressive Strength & $1258 \mathrm{MPa}$ \\
Compressive Modulus & $56 \mathrm{GPa}$ \\
Cured Ply Thickness & $0.18 \mathrm{~mm}$ \\
Fibre Weight & $300 \mathrm{~g} / \mathrm{m}^{2}$ \\
Prepreg Areal Weight & $476 \mathrm{~g} / \mathrm{m}^{2}$ \\
\hline
\end{tabular}

Table 2. Physical and chemical properties of AIREX® T92.100 foam.

\begin{tabular}{ll}
\hline \multicolumn{1}{c}{ Physical state or form } & Polymer foam sheet with visible cell structures \\
\hline Colour & White \\
Melting temperature & $250{ }^{\circ} \mathrm{C}$ \\
Decomposition temperature & $>340^{\circ} \mathrm{C}$ \\
Flash ignition temperature & $370{ }^{\circ} \mathrm{C}$ \\
Density & $100-320 \mathrm{~kg} / \mathrm{m}^{3}$ \\
\hline
\end{tabular}

\section{Impact Perforation of the Sandwich Structures}

The impact response of the sandwich structures was assessed using an instrumented dropweight impact rig. Here, a $5.6 \mathrm{~kg}$-carriage of impact mass, with a $12-\mathrm{mm}$ diameter steel hemispherical indenter was used to strike impact energies up to $40 \mathrm{~J}$ at normal $\left(0^{\circ}\right)$ and oblique angles of $10^{\circ}$ and $20^{\circ}$. The impact velocity measured was at approximately up to $3.78 \mathrm{~m} / \mathrm{s}$. A close view of the oblique impact test set-up is shown in Figure 2 with the sandwich panel fully clamped using a 100-mm diameter circular steel ring 


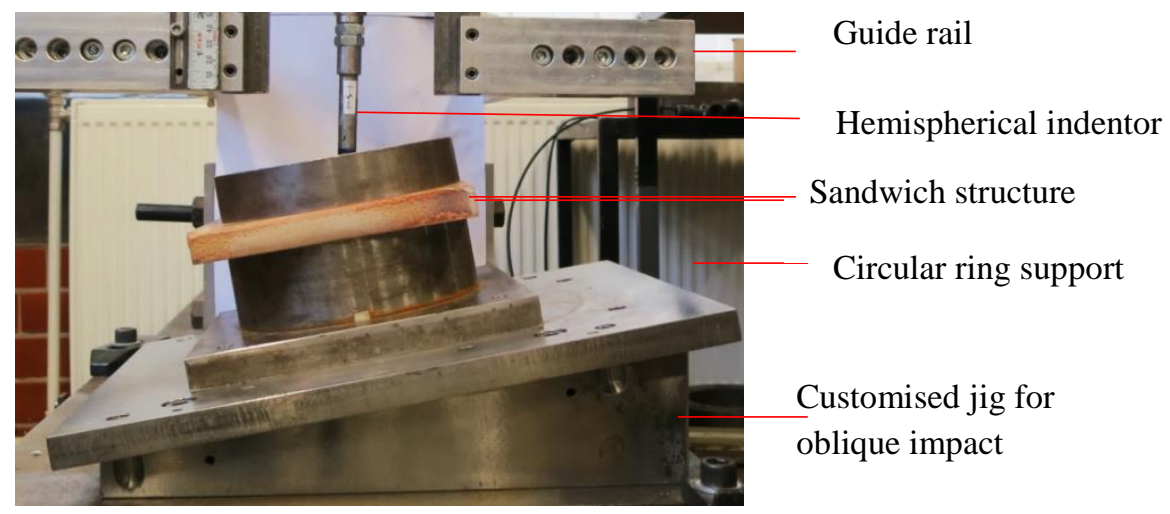

Figure 2. Experimental setup during an oblique impact test on a sandwich structures.

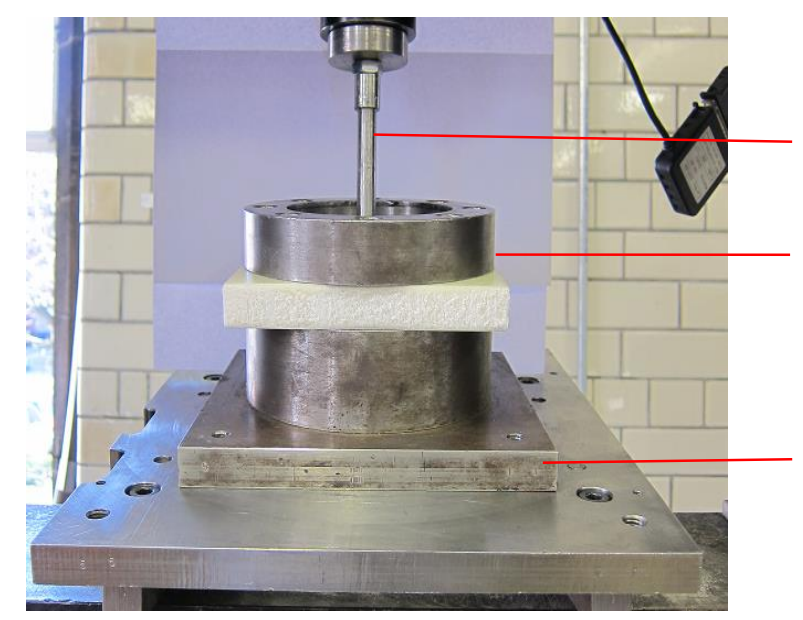

12-mm diameter hemispherical steel indentor 150-mm diameter circular steel ring for clamping

Customised jig for test at inclined angle

(a)

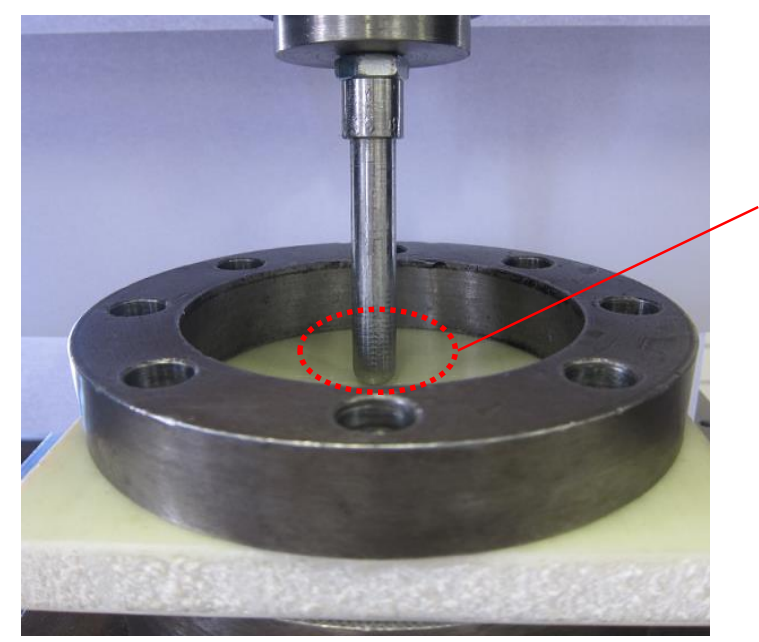

A close view showing contact surface between the indentor and the sandwich panel during an indentation test

(b)

Figure 3 A static indentation test set-up using the oblique impact test rig, showing (a) quasi-static indentation test set-up sandwich panels loaded at $10^{\circ}$ of inclination; (b) A closer view showing contact between the hemispherical indenter and the inner surface of the sandwich panel. 


\section{Indentation Test}

A series of indentation tests were carried out using an Instron 4505 test machine at a crosshead displacement rate of $1 \mathrm{~mm} /$ minutes under compression loading mode. Like the dynamic loading, the test samples were centrally loaded with similar boundary condition in which the test samples were fully clamped using the same circular steel ring. For tests at inclined angles, a customised jig was used as shown in Figure 3. The working principle of this test was based on the contact law for sandwich structures [22], in which the applied load, $P$, and the resulting indentation, $\alpha$, were assumed to obey Meyer's indentation law, which takes the form of the expression in Equation (1) as follows:

$$
P=C \propto^{n}
$$

where $C$ and $n$ are constants determined by fitting the experimental data to this relationship. This information was explained in the previous work by Fadzullah and Cantwell [23].

\section{Mathematical Modelling}

In this study, based on the past literature [19] for both the normal and oblique impact cases, the perforated area can be predicted using a simple geometric analysis, where the ratio of the surface area of an elliptical oblique cylinder to that of a right cylinder in which the indenter creates an elliptical entrance hole on the top surface of the target, which can be expressed by Eqs. (2) and (3) as follows.

$$
\frac{\sqrt{\frac{1}{2}\left(r^{2}+R^{2}\right)}}{r \cos (I)}-1
$$

where, $r$ is the radius of the right cylinder, $R$ is the long radius of the elliptical oblique cylinder, and $I$ is the angle between the right and elliptical oblique cylinder.

$$
\frac{1}{\cos (I)}-1
$$

\section{RESULTS AND DISCUSSION}

Examples of typical load-time traces following drop-weight impact at $0^{\circ}, 10^{\circ}$, and $20^{\circ}$ angles are given in Figure 4, whilst detail results are tabulated in Table 3. The plots consist of three main regions; the first peak (1), which is associated with the failure or fracture of the top skin, the second peak (3), which is associated with the failure of the lower skin, and the region in between the two peaks (2), which indicates the average force of the sandwich structures. Clearly, the normal impact response exhibits a much higher force in comparison to that of the non-normal impact cases. Similar observations were reported in an early literature by [2] on low-velocity impact response of normal and oblique impact on composite structures with specific governing equations for the system of forces present during the normal and non-normal or oblique impact. The range of impact velocity for the series of experimental test in the study was up to $5.42 \mathrm{~m} / \mathrm{s}$. More recently, Zhou et al. [19] also reported on similar findings following numerical modelling and experimental investigation of the normal and oblique impact on sandwich structures. 


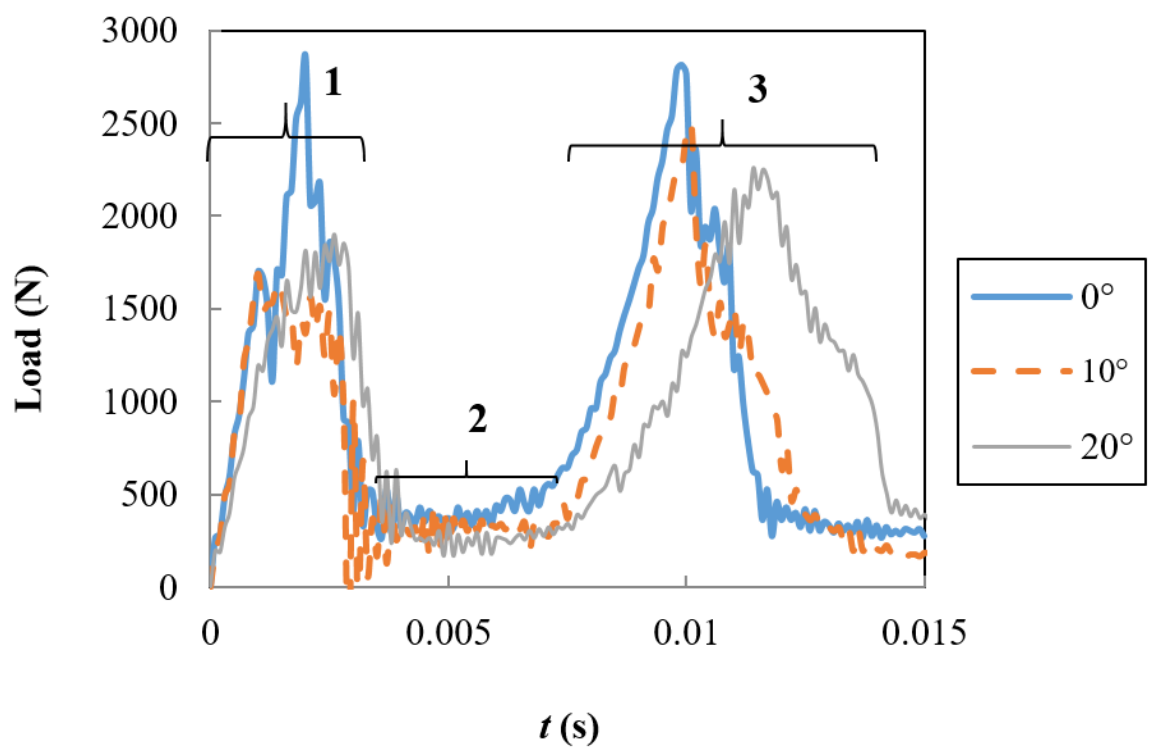

Figure 4. Typical load-time traces following dynamic perforation test (impact test) on the PET (T92.100) sandwich structures with $0^{\circ}, 10^{\circ}$, and $20^{\circ}$ inclination angles.

Table 3. Experimental results following low-velocity impact test on the PET sandwich structures at normal and oblique angles.

\begin{tabular}{lcccc}
\hline $\begin{array}{l}\text { Type of foam core } \\
\text { sandwich structures }\end{array}$ & $\begin{array}{c}\text { Impact } \\
\text { angle }\left({ }^{\circ}\right)\end{array}$ & $1^{\text {st }}$ Peak (N) & $2^{\text {nd }}$ Peak (N) & $\begin{array}{c}\text { Average } \\
\text { Force }(\mathrm{N})\end{array}$ \\
\hline T92.100 & 0 & $2850 \pm 114$ & $2811 \pm 141$ & $372 \pm 7$ \\
& 10 & $1687 \pm 59$ & $2492 \pm 63$ & $337 \pm 6$ \\
& 20 & $1812 \pm 72$ & $2249 \pm 108$ & $298 \pm 6$ \\
\hline
\end{tabular}

In addition to the response following impact testing, quasi-static perforation tests were also conducted to assess the correlation between both types of loading conditions subjected to the three inclination angles. For example, Figure 5 gives typical loaddisplacement traces following quasi-static perforation tests and impact loading on the PET T92.100 sandwich panels at $0^{\circ}, 10^{\circ}$, and $20^{\circ}$ inclination angles. Under both types of loading condition, similar trends were observed, consisting of three main regions. The first region exhibited an initial peak, which corresponded to fracture of the top skin. Following this, in the second region, the load gradually dropped and remained constant, which corresponded to the point where the indenter was perforating the foam core. This force was greatly dependent on the fracture properties of the core [24, 25]. Lastly, the third region was a final peak, which was associated with failure of the lower composite skin [26]. From the load-displacement traces, it was apparent that the dynamic load required to cause a given deflection was higher than the load required to cause the same deformation under quasi-static loading regardless of whether the test was conducted at normal (Figure 4) or at oblique angles (Figure 5). Here, $0^{\circ}$ loading resulted in a higher initial first peak force, a higher average force as well as a higher second peak force. These observations were attributed to the inertial effects and the material's strain-rate sensitivity [24] as given in Table 4. 
Table 4. Comparison between the results following quasi-static and impact loading on PET (T92.100) sandwich structures at normal and oblique angles.

\begin{tabular}{lcccccc}
\hline $\begin{array}{l}\text { Type of } \\
\text { Loading }\end{array}$ & $\begin{array}{c}\text { Impact } \\
\text { angle } \\
\left({ }^{\circ}\right)\end{array}$ & $\begin{array}{c}1^{\text {st }} \text { Peak } \\
(\mathrm{N})\end{array}$ & $\begin{array}{c}2^{\text {nd }} \text { Peak } \\
(\mathrm{N})\end{array}$ & $\begin{array}{c}\text { Average } \\
\text { Force (N) }\end{array}$ & $\begin{array}{c}\text { Perforation } \\
\text { Energy (J) }\end{array}$ & $\begin{array}{c}\text { Dynamic } \\
\text { enhancement } \\
\text { factor, } \Phi\end{array}$ \\
\hline $\begin{array}{l}\text { Quasi- } \\
\text { Static }\end{array}$ & $0^{\circ}$ & $1425 \pm 29$ & $1296 \pm 45$ & $302 \pm 9$ & $13.7 \pm 0.2$ & 1.8 \\
$\begin{array}{l}\text { Dynamic } \\
\text { Quasi- }\end{array}$ & & $2850 \pm 114$ & $2811 \pm 141$ & $372 \pm 7$ & $25.2 \pm 3$ & \\
$\begin{array}{l}\text { Static } \\
\text { Dynamic }\end{array}$ & $10^{\circ}$ & $1110 \pm 28$ & $1128 \pm 39$ & $311 \pm 6$ & $15.5 \pm 0.4$ & 2.15 \\
$\begin{array}{l}\text { Quasi- } \\
\text { Static }\end{array}$ & $20^{\circ}$ & $1687 \pm 59$ & $2492 \pm 63$ & $337 \pm 6$ & $33.3 \pm 1.4$ & \\
Dynamic & & $1812 \pm 72$ & $2249 \pm 108$ & $298 \pm 6$ & $28.8 \pm 2.4$ & 2.4 \\
\hline
\end{tabular}

Similarly, the perforation energies under impact loading were higher than the quasi-static values for all the inclination angles considered. In addition, it was observed that the perforation energy increased with inclination angle in Figure 5 (b) which is in agreement with the work by Zhou et al. [19]. Referring to an earlier study by Wen et al. [21], the dynamic enhancement factor, $\Phi$, which is defined as the ratio of the dynamic perforation energy for a panel to the energy absorbed up the fracture of the lower skin of an identical panel under quasi-static loading was considered. This parameter is shown to increase with inclination angle as listed in Table 5.

Table 5. The percentage increase in surface area and volume of an elliptical oblique cylinder relative to that of a right cylinder using a simple geometric analysis [19].

\begin{tabular}{lcc}
\hline$I$ & $10^{\circ}$ & $20^{\circ}$ \\
$r$ & $6 \mathrm{~mm}$ & $6 \mathrm{~mm}$ \\
$R$ & $r \cos \left(10^{\circ}\right)$ & $r \cos \left(20^{\circ}\right)$ \\
Surface area increase in percentage $(\%)$ & 1.54 & 6.42 \\
Volume increase in percentage $(\%)$ & 2.33 & 9.89 \\
\hline
\end{tabular}

The PET foam core is a rigid polymeric material; therefore, such material is expected to show a more brittle-like failure when subjected to impact loading [24] particularly at higher energies. Figure 6 presents the cross-section result following a series of quasi-static tests on PET (T92.100) foam core sandwich panels supported at inclination angles of $0^{\circ}, 10^{\circ}$, and $20^{\circ}$. As shown in Figure 6 (a), it was evident that the panel loaded quasi-statically at $0^{\circ}$ exhibited both a cylindrical shear zone in the foam core and a tensile cone crack in the top skin. Interestingly, up to a displacement of $25 \mathrm{~mm}$, the indenter did not fully perforate the panel under static loading. In Figure 6 (b), at $10^{\circ}$, it was apparent that the penetrating surface was larger with the shape now being more elliptical and finally at $20^{\circ}$, evidence of significant rear surface damage was apparent as shown in Figure 6 (c). 


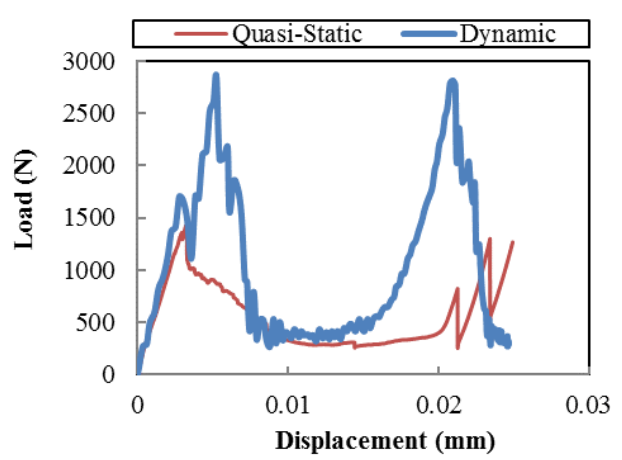

(a)

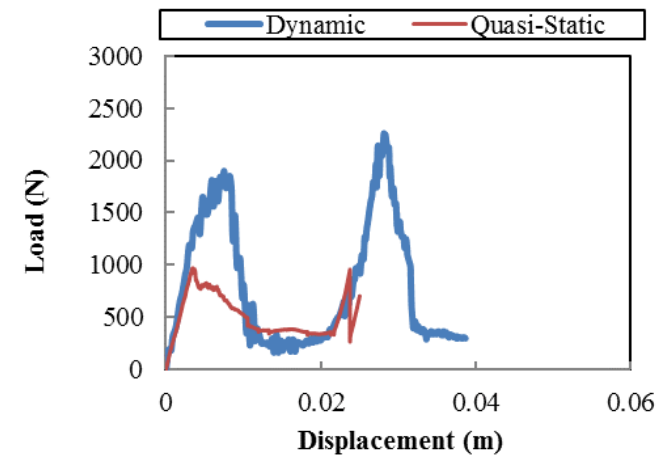

(b)

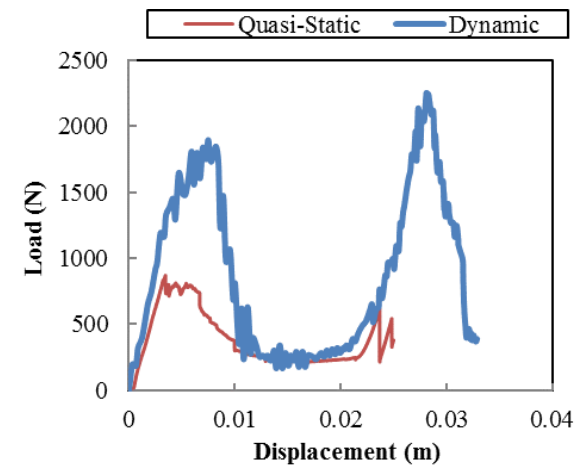

(c)

Figure 5. Load-displacement traces following quasi-static and impact loading on the PET (T92.100) sandwich structures at (a) $0^{\circ}$, (b) $10^{\circ}$, and (c) $20^{\circ}$ impact angle.

Figure 7 presents the corresponding optical micrographs showing the perforation behaviour at the cross-sections. In Figure 7 (a), it was apparent that the sandwich panel subjected to normal impact exhibited tensile failure of the top skin and shearing of the foam core. In addition, the lower skin underwent full perforation and therefore significant tensile fracture of the lower skin was apparent. In Figure $7(\mathrm{~b})$, at $10^{\circ}$, it was apparent that the penetrating surface is larger with the shape now being more elliptical. Finally, at $20^{\circ}$, evidence of significant rear surface damage was apparent as shown in Figure 7(c). These observations can be quantified using a simple geometric analysis, where the ratio of the surface area of an elliptical oblique cylinder to that of a right cylinder in which the projectile creates an elliptical entrance hole on the top surface of the target, as given in Equations (1) and (2). In this work, two cases were considered; i.e., inclination angles of $10^{\circ}$ and $20^{\circ}$ relative to the normal $\left(\theta: 0^{\circ}\right)$. Therefore, considering that $r$ is $6 \mathrm{~mm}, R$ is taken as $r \cos (\theta)$, the ratio of the surface area of an elliptic oblique cylinder to that of the right cylinder is given in Table 5. It was apparent that with an increase in inclination angle, the larger surface area was created during perforation of the sandwich panels. For the case of $10^{\circ}$, there was an increase of $1.54 \%$ in terms of the surface area and $2.33 \%$ of the volume. For the case of $20^{\circ}$ loading, the increase in surface area was $6.42 \%$ and $9.89 \%$ by volume. These observations further explain the reasons for the increase in the perforation energy, in passing from a normal impact to an oblique impact at an angle of $20^{\circ}$. These observations suggest that perforation at oblique angles allow more materials to be perforated as was reported in the literature [19]. 


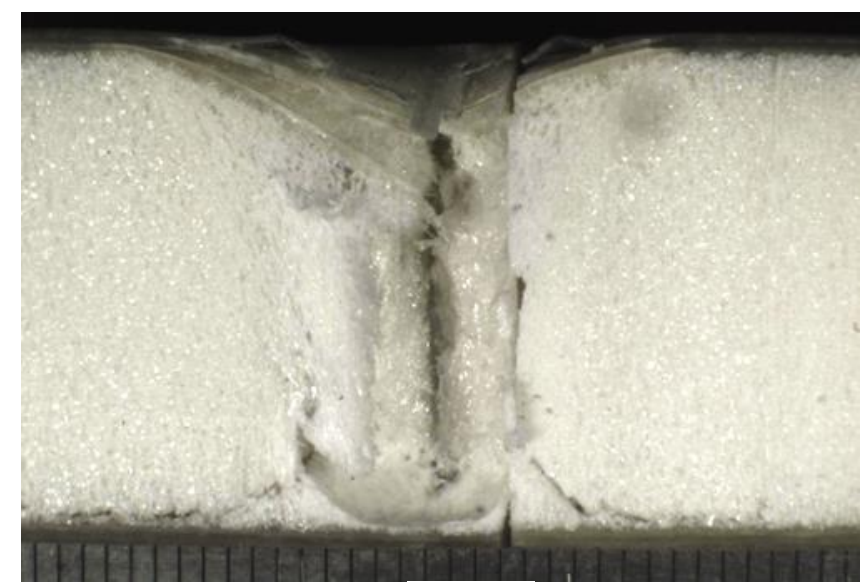

(a)

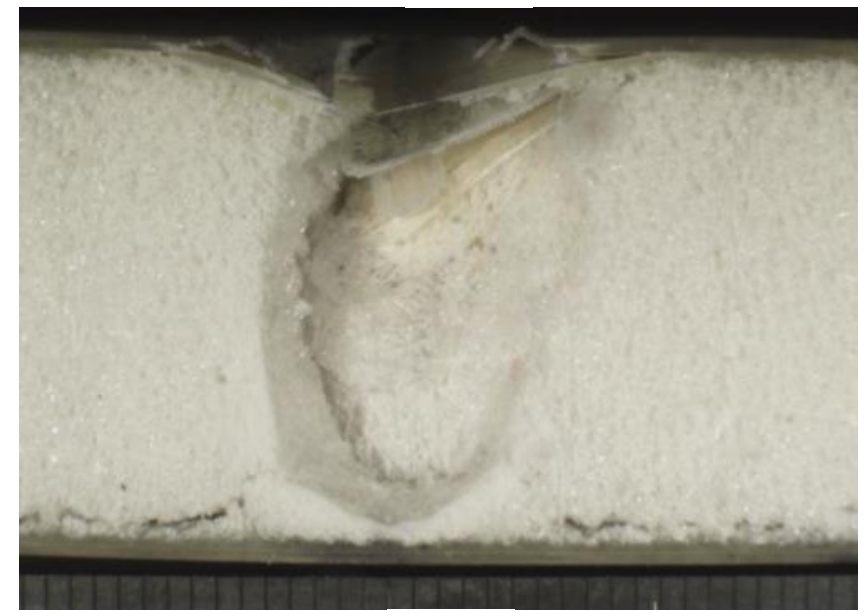

(b)

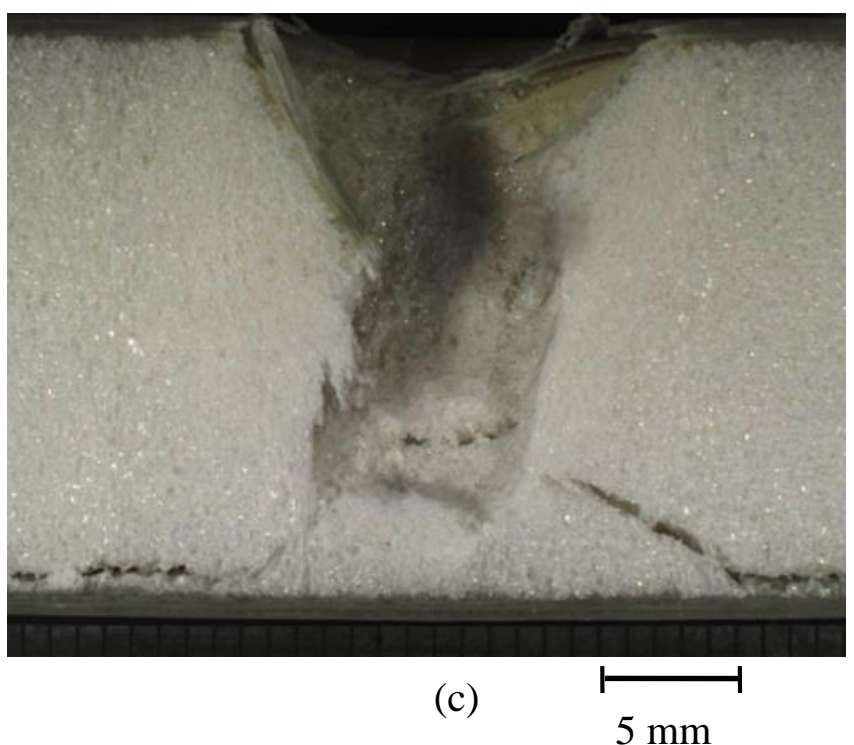

Figure 6. Optical micrographs showing the cross-sections of the PET (T92.100) sandwich structures following quasi-static loading at inclination angles of (a) $0^{\circ}$, (b) $10^{\circ}$, and (c) $20^{\circ}$. 


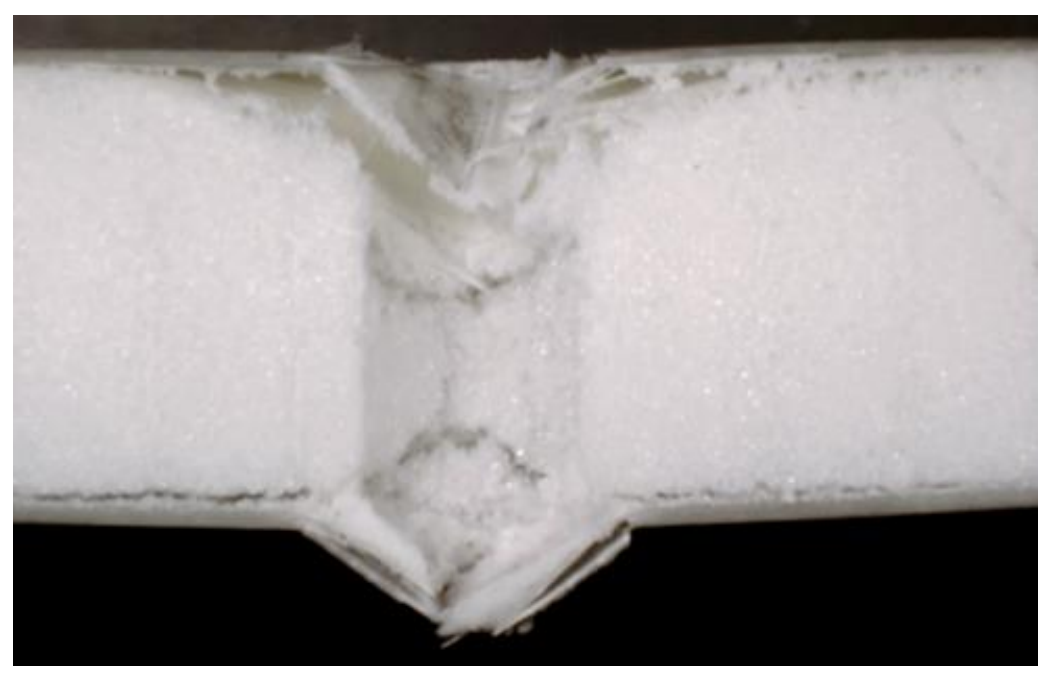

(a)

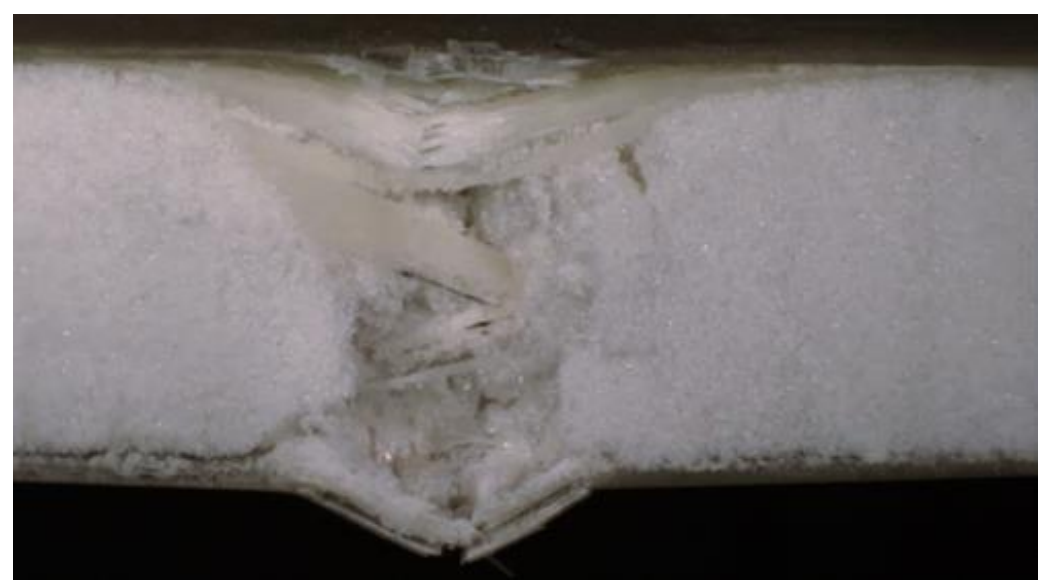

(b)

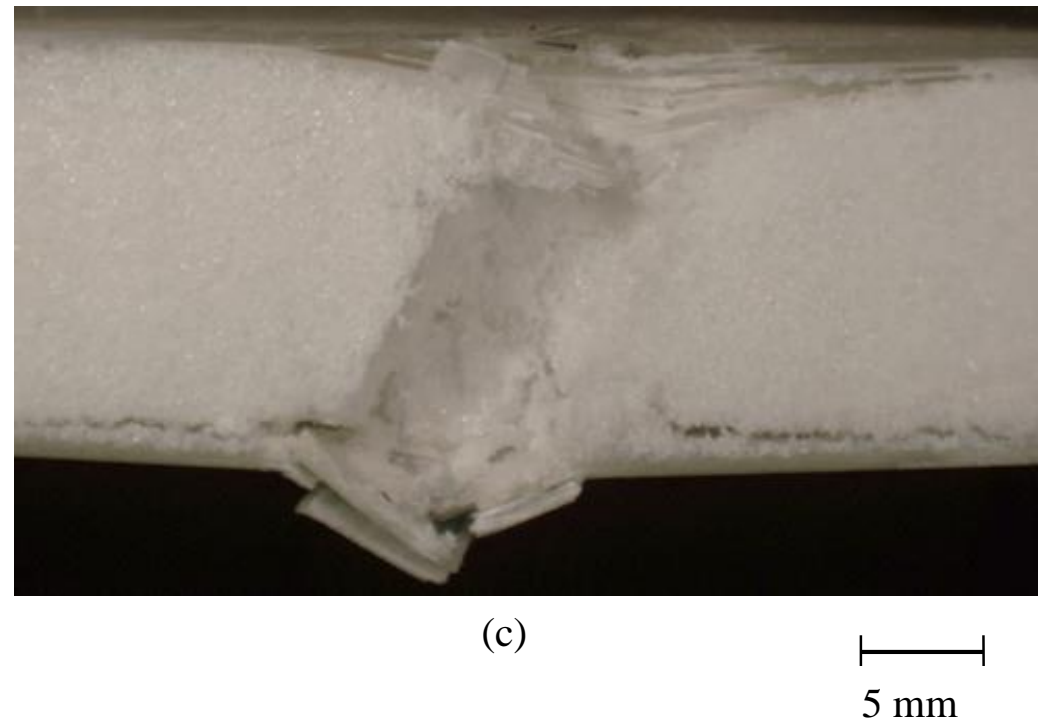

Figure 7. Optical micrographs showing the cross-sections of the PET (T92.100) sandwich structures following impact perforation tests $(40 \mathrm{~J})$ at inclination angles of (a) $0^{\circ}$, (b) $10^{\circ}$, and (c) $20^{\circ}$. 


\section{CONCLUSIONS}

In this paper, several conclusions have been drawn based on the experimental results following quasi-static and dynamic loading on PET foam cored sandwich composites subjected to normal and oblique angles at energies up to $40 \mathrm{~J}$. Overall, it can be concluded that it is the normal impact that results in the highest peak force for both the first and second peaks, which are associated with the damage to the top and bottom skin of the sandwich structures, respectively. In addition, both the first and the second peaks were reduced with the increasing inclination angle in passing from $0^{\circ}$ to $20^{\circ}$. However, in terms of the average force, which corresponded to densification of the foam core, the value showed an increase with the inclination angle. In addition, regardless of whether the test was conducted at normal or other inclination angles, it was the response from dynamic loading (impact test) that resulted in higher force magnitude, when compared between the quasi-static and dynamic response of the PET-based sandwich structures. In terms of the damage profiles, from the morphological study at the cross-sections, it was evident that the maximum damage area increased with the increasing inclination angle in passing from $0^{\circ}$ up to $20^{\circ}$, as supported by simple geometric analysis in quantifying the percentage increase in Eq. (2). This suggests the combined effect of tensile, compression and shear for impact at $10^{\circ}$ in comparison to pure shearing for the $20^{\circ}$ impact case. In other words, the perforation behaviour at inclined angles allowed more area to be perforated in comparison to those of the normal cases.

\section{ACKNOWLEDGEMENTS}

The authors are grateful to Prof. Wesley Cantwell and Mr. Stephen Pennington from University of Liverpool, UK for the technical support. Special thanks to Universiti Teknikal Malaysia Melaka (UTeM) and Ministry of Education Malaysia under Research Acculturation Grant Scheme RAGS/1/2014/TK04/FKM/B00069 for the financial support.

\section{REFERENCES}

[1] Iváñez I, Moure M, Garcia-Castillo S, Sanchez-Saez S. The oblique impact response of composite sandwich plates. Composite structures. 2015;133:1127-36.

[2] Madjidi S, Arnold W, Marshall I. Damage tolerance of csm laminates subject to low velocity oblique impacts. Composite structures. 1996;34:101-16.

[3] Hazizan MA, Cantwell W. The low velocity impact response of an aluminium honeycomb sandwich structure. Composites Part B: Engineering. 2003;34:67987.

[4] Tan C, Akil HM. Impact response of fiber metal laminate sandwich composite structure with polypropylene honeycomb core. Composites Part B: Engineering. 2012;43:1433-8.

[5] Khalili P, Tarlochan F, Hamouda AMS, Al-Khalifa K. Energy absorption capability of thin-walled aluminium tubes under crash loading. Journal of Mechanical Engineering and Sciences. 2015;9:1734-43.

[6] Mohamad M, Marzuki HFA, Bakar SNA, Abdullah AN, Ubaidillah EAE, Abidin MFZ, et al. Effect of anodizing electrolyte for structural adhesives bonding study 
of aluminium-carbon laminates composites. International Journal of Automotive and Mechanical Engineering. 2014;10:2091-101.

[7] Hafizi ZM, Epaarachchi J, Lau KT. An investigation of acoustic emission signal attenuation for monitoring of progressive failure in fiberglass reinforced composite laminates. International Journal of Automotive and Mechanical Engineering. 2013;8:1442-56.

[8] Ghaffari S, Tan T, Awerbuch J. An experimental and analytical investigation on the oblique impact of graphite/epoxy laminates. 22nd International SAMPE Technical Conference, November1990.

[9] Bouadi H, Marple Jr L, Marshall A. Normal and oblique impact damage on thicksection composite laminates. ASME AEROSP DIV PUBL AD, ASME, NEW YORK, NY(USA), 1992. 1992;30:157-69.

[10] Sierakowski RL, Chaturvedi SK. Dynamic loading and characterization of fiberreinforced composites. Dynamic Loading and Characterization of FiberReinforced Composites, by Robert L Sierakowski, Shive K Chaturvedi, pp 252 ISBN 0-471-13824-X Wiley-VCH, February 1997. 1997:252.

[11] Haris A, Tay TE, Tan VBC. Experimental analysis of composite bolted joints using digital image correlation. Journal of Mechanical Engineering and Sciences. 2017;14:2443-55.

[12] Maleque MA, Radhi M, Rahman MM. Wear study of mg-sicp reinforcement aluminium metal matrix composite. Journal of Mechanical Engineering and Sciences. 2016;10:1758-64.

[13] Lamontage CG, Manuelpillai GN, Taylor EA, Tennyson RC. Normal and oblique hypervelocity impacts on carbon fibre/peek composites. International Journal of Impact Engineering. 1999;23:519-32.

[14] López-Puente J, Zaera R, Navarro C. Experimental and numerical analysis of normal and oblique ballistic impacts on thin carbon/epoxy woven laminates. Composites Part A: Applied Science and Manufacturing. 2008;39:374-87.

[15] Xia F, Wu X. Work on low-velocity impact properties of foam sandwich composites with various face sheets. Journal of reinforced plastics and composites. 2010;29:1045-54.

[16] Zhu S, Chai GB. Damage and failure mode maps of composite sandwich panel subjected to quasi-static indentation and low velocity impact. Composite structures. 2013;101:204-14.

[17] Hazell P, Kister G, Stennett C, Bourque P, Cooper G. Normal and oblique penetration of woven cfrp laminates by a high velocity steel sphere. Composites Part A: Applied Science and Manufacturing. 2008;39:866-74.

[18] Zaera R, Sánchez-Gálvez V. Analytical modelling of normal and oblique ballistic impact on ceramic/metal lightweight armours. International Journal of Impact Engineering. 1998;21:133-48.

[19] Zhou J, Hassan MZ, Guan Z, Cantwell WJ. The low velocity impact response of foam-based sandwich panels. Composites Science and Technology. 2012;72:1781-90.

[20] Abrate S. Impact on composite structures: Cambridge University Press; 2005.

[21] Wen H, Reddy T, Reid S, Soden P. Indentation, penetration and perforation of composite laminate and sandwich panels under quasi-static and projectile loading. Key Engineering Materials: Trans Tech Publ; 1998. p. 501-52.

[22] Hazizan MA, Cantwell W. The low velocity impact response of foam-based sandwich structures. Composites Part B: Engineering. 2002;33:193-204. 
[23] Fadzullah SSM, Cantwell W. The effect of angle of incidence on the impact response of composites and sandwich structures. 15th European conference on composite materials, Venice, Italy, 24-28 June 2012, p.1-8.

[24] Hassan M, Cantwell W. The influence of core properties on the perforation resistance of sandwich structures-an experimental study. Composites Part B: Engineering. 2012;43:3231-8.

[25] Lee L, Huang K, Fann Y. Dynamic responses of composite sandwich plate impacted by a rigid ball. Journal of Composite Materials. 1993;27:1238-56.

[26] Lee S-W, Sun CT. Dynamic penetration of graphite/epoxy laminates impacted by a blunt-ended projectile. Composites Science and Technology. 1993;49:369-80. 